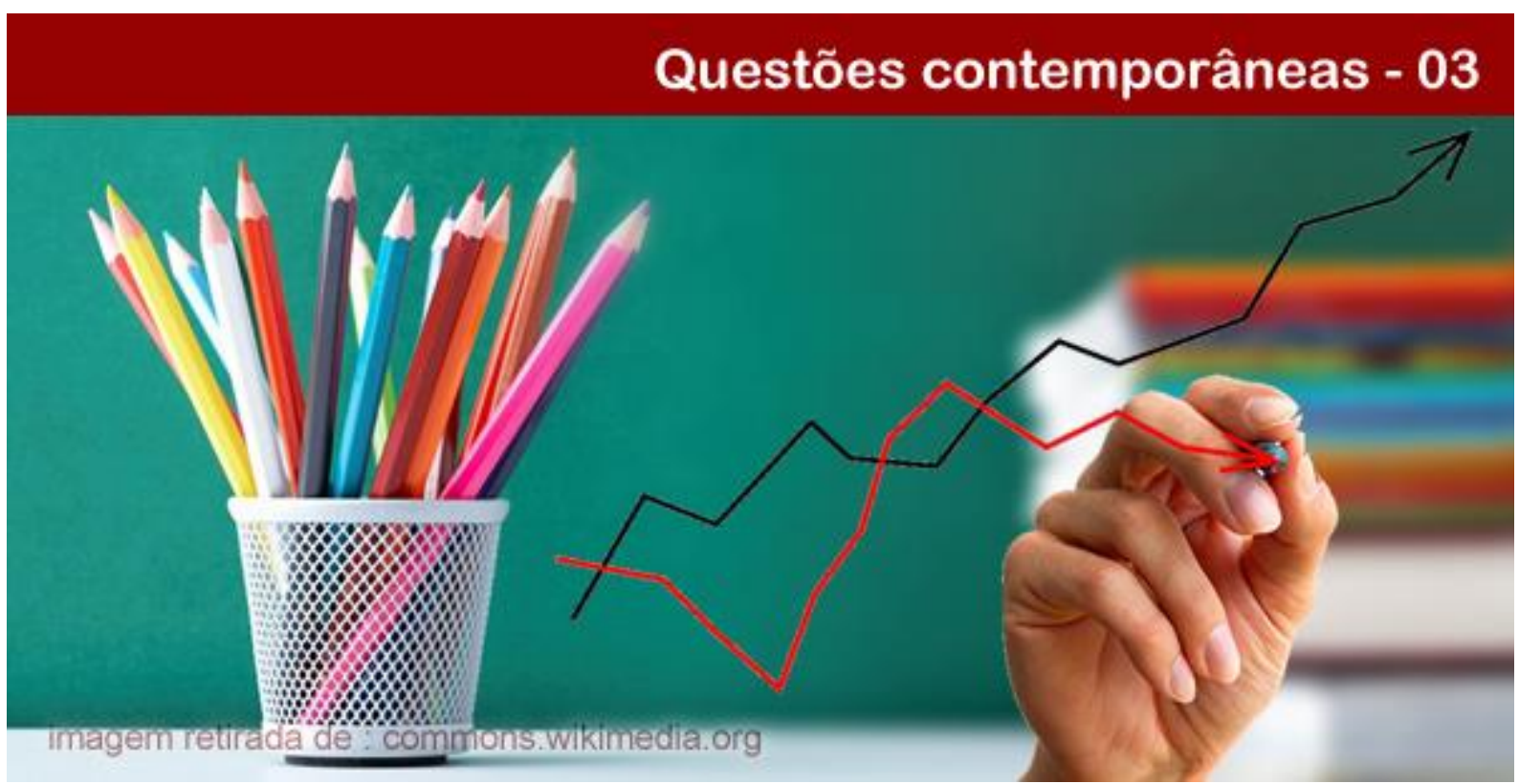

\title{
GESTÃO DA ESCOLA E OS RESULTADOS DO IDEB: APROPRIAÇÕES E USOS DE DADOS EDUCACIONAIS
}

\author{
Maria Adalgiza de Farias \\ Técnica em Educação da Secretaria Municipal de Educação da Prefeitura de Fortaleza. Mestre em Educação e \\ graduada em Pedagogia pela Universidade Estadual do Ceará (UECE). Cursando Graduação em Administração \\ pela Universidade Estácio de Sá e Especialização em Gestão Pública pela UECE. E-mail: giza28@ gmail.com.

\section{Antonio Germano Magalhães Junior} \\ Professor do Programa de Pós-Graduação em Educação da Universidade Estadual do Ceará (UECE). Pós- \\ Doutorado em Educação pela Universidade Federal do Rio Grande do Norte (UFRN). Doutor e Mestre em \\ Educação pela Universidade Federal do Ceará (UFC).E-mail: germano.junior@uece.br.
}

Resumo: Este artigo é resultado de uma pesquisa que enfoca as mudanças no cenário educacional brasileiro, iniciadas com a reformulação do Sistema de Avaliação da Educação Básica (SAEB), em 2005, e com a aferição da qualidade da educação pelo Índice de Desenvolvimento da Educação Básica (IDEB), para o cumprimento do Plano de Metas Compromisso Todos pela Educação. O objetivo foi analisar como os dados IDEB foram apropriados e utilizados em escolas públicas municipais de Fortaleza, a partir da perspectiva da equipe de gestão, tendo em vista os desafios das escolas no tocante às metas de qualidade educacional. O estudo abrange três escolas que conseguiram evoluir continuamente as metas do IDEB, nas duas etapas do Ensino Fundamental ( $5^{\circ}$ e $9^{\circ}$ anos $)$, nas edições de 2007 a 2013. Os atores foram os gestores da época. A pesquisa foi desenvolvida por meio de entrevistas e análise documental. O estudo mostrou que os atores utilizavam, de fato, os resultados do sistema de avaliação próprio do Governo do Estado do Ceará e evidenciou a necessidade de que gestores e professores buscassem conhecer melhor os resultados de sua instituição nas avaliações externas para utilizá-los como insumos estratégicos no desenvolvimento de projetos educativos, considerando a possibilidade de melhoria das condições de aprendizagem no ambiente escolar.

Palavras-chave: Política educacional. IDEB. Gestão da escola. Uso de dados educacionais.

\section{POLÊM!CA $\mid$ LABORE}

Polêmica - Revista Eletrônica da Uerj - Rua São Francisco Xavier, 524, $1^{\circ}$ andar bloco D, sl.1001 • Tels.: +55 21 2334-4088 / 4087 • http://www.e-publicacoes.uerj.br/index.php/polemica/index http://www.labore.uerj.br • laboreuerj@yahoo.com.br 


\title{
MANAGEMENT OF SCHOOL AND THE RESULTS OF IDEB: APPROPRIATIONS AND USES OF EDUCATIONAL DATA
}

\begin{abstract}
This article is the result of a research that focuses on the changes in the Brazilian educational scenario, which started with the reformulation of the Basic Education Assessment System (SAEB) in 2005, and with the quality of education assessment by the Basic Education Development Index (IDEB), in order to fulfill the Plan of Goals Commitment All for Education. The objective was to analyze how the IDEB data were appropriated and used in municipal public schools of Fortaleza from the perspective of the management team, based on the challenges of the schools regarding the goals of educational quality. The study covers three schools that were able to continuously evolve the goals of the IDEB in the two stages of elementary school (5th and 9th years), in the editions from 2007 to 2013, and the actors were the managers of the time. The research was developed through interviews and documentary analysis. The study showed that the actors actually used the results of the evaluation system of the Government of the State of Ceará and pointed out the need for managers and teachers to better understand the results of their institution in the external evaluations to use them as inputs strategies in the development of educational projects, considering the possibility of improving the learning conditions in the school environment.
\end{abstract}

Keywords: Educational politics. IDEB. School management. Use of educational data.

\section{Introdução}

O presente artigo é resultado de uma pesquisa que enfoca as mudanças no cenário educacional brasileiro, iniciadas com a reformulação do Sistema de Avaliação da Educação Básica (SAEB), pela portaria Ministerial № 931, de 21 de março de 2005, que modificou seu caráter histórico de exame amostral no Ensino Fundamental ao ampliar sua dimensão. Este sistema passou a ser composto por dois processos avaliativos: Avaliação Nacional da Educação Básica (ANEB), e Avaliação Nacional do Rendimento Escolar (ANRESC), conhecida como Prova Brasil, conforme explicitado nas páginas a seguir.

Com a reformulação do SAEB, em 2005, a avaliação externa tornou-se eixo da política educacional brasileira, tendo por base a aferição da qualidade da educação pelo Índice de Desenvolvimento da Educação Básica (IDEB), para o cumprimento do Plano de Metas Compromisso Todos pela Educação. Nesta conjuntura, o repasse de recursos financeiros pelo Fundo Nacional de Desenvolvimento Educacional (FNDE) aos entes federados passou a vincular-se ao compromisso dos gestores municipais e estaduais com determinadas metas de melhoria dos seus indicadores apresentados nas avaliações externas (BRASIL, 2007).

Em consequência dos compromissos assumidos pelos entes federados, os sistemas de ensino e as escolas passaram a assumir maior responsabilidade na promoção e êxito dos seus alunos, tendo como referencial o IDEB, que combina dois outros indicadores: dados sobre o rendimento escolar, obtidos pelo Censo Escolar, e desempenho dos alunos na Prova Brasil.

A Prova Brasil é um exame que envolve todos os alunos do $5^{\circ}$ e do $9^{\circ}$ ano das escolas públicas que tenham, no mínimo, 20 alunos matriculados nos anos avaliados, e tem como

\section{POLÊM!CA $\mid$ LABORE}

Polêmica - Revista Eletrônica da Uerj - Rua São Francisco Xavier, $524,1^{\circ}$ andar bloco D, sl.1001 • Tels.: +55 21 2334-4088 / 4087 • http://www.e-publicacoes.uerj.br/index.php/polemica/index http://www.labore.uerj.br • laboreuerj@yahoo.com.br 
objetivo avaliar habilidades e competências dos estudantes nas áreas de Língua Portuguesa e Matemática. Os testes são realizados pelo Instituto Nacional de Estudos e Pesquisas Educacionais Anísio Teixeira (INEP/MEC), e os resultados são disponibilizados numa escala de proficiência por escola e por ente federativo.

No âmbito escolar, a equipe gestora é responsável por viabilizar a organização do seu espaço educativo, para o alcance dos seus objetivos e metas educacionais, o que aponta a necessidade de que professores e gestores compreendam, se apropriem e saibam utilizar os dados obtidos nas avaliações externas como elementos essenciais para o planejamento e avaliação da instituição escolar.

Assim, as avaliações externas vão numa perspectiva de se produzir informações que podem motivar atitudes a serem tomadas, no sentido de se criar condições para que os sistemas de ensino e as escolas reconheçam nos resultados as possibilidades de superar as dificuldades identificadas. Sobre essa perspectiva, realizou-se uma pesquisa que procurou responder a seguinte pergunta: os dados do IDEB são utilizados na gestão das escolas públicas municipais de Fortaleza para (re)orientar o planejamento e identificar dificuldades a serem superadas?

O objetivo desta pesquisa foi analisar como os dados do IDEB foram apropriados e utilizados para a gestão da educação pública municipal de Fortaleza e traduzidos no cotidiano escolar por meio das ações de membros de equipes de gestão do período de 2005 a 2013. Especificamente, buscou-se: 1) compreender como a equipe de gestão se apropriou e utilizou os resultados do IDEB para (re)organizar suas ações nas escolas; 2) elucidar as principais ações/decisões adotadas pelos gestores que resultaram na evolução das metas do IDEB; e 3) analisar a relação entre o Projeto Político-Pedagógico (PPP) e o trabalho dos gestores quanto a melhoria das taxas de fluxo escolar e desempenho dos alunos na Prova Brasil (Português e Matemática).

A relevância desse estudo se deu pela importância de analisar como os atores dessa pesquisa (membros da equipe de gestão da Secretaria Municipal de Educação e das escolas) interpretam e colocam a política em ação, partindo do princípio de que os envolvidos nesse processo não são meros implementadores de políticas.

O campo de pesquisa delimitou-se a três escolas de Ensino Fundamental completo $\left(1^{\circ}\right.$ a $9^{\mathbf{o}}$ anos) que conseguiram atingir e/ou superar continuamente as metas do IDEB projetadas para as edições de 2007 a 2011 . Os atores foram profissionais que atuaram como membros da equipe

\section{POLÊM!CA $\mid$ LABORE}

Polêmica - Revista Eletrônica da Uerj - Rua São Francisco Xavier, 524, $1^{\circ}$ andar bloco D, sl.1001 • Tels.: +55 21 2334-4088 / 4087 • http://www.e-publicacoes.uerj.br/index.php/polemica/index http://www.labore.uerj.br • laboreuerj@yahoo.com.br 
de gestão das unidades investigadas e um gestor da Secretaria Municipal de Educação que atuou nesse período, considerando que as três escolas são orientadas pela mesma política de rede.

O aporte teórico selecionado para o presente estudo revela a necessidade de se perceber o que a gestão da educação municipal e escolas têm feito para superar o debate conceitual sobre as políticas educacionais que sugerem uma tendência acompanhada pelas exigências de superar uma lógica pautada na busca de resultados educacionais, tendo como marco temporal o ano de 2005, quando foi criada a Prova Brasil.

\section{Universo da pesquisa e os casos selecionados}

A capital cearense tem o quarto maior sistema municipal de educação do Brasil ${ }^{1}$, abrigando um total de 138.153 crianças e adolescentes, matriculados no Ensino Fundamental em 295 unidades escolares ${ }^{2}$ no ano letivo de 2013.

Para a seleção dos casos (escolas), adotou-se como critério básico a variável "Resultado do IDEB”, priorizando-se a continuidade das metas atingidas e/ou superadas pelas escolas em relação à sua projeção definida pelo INEP.

Os procedimentos realizados para a seleção dos casos e critérios utilizados para delimitação da amostra se deram em outubro de 2013, a partir da obtenção de arquivos do Portal do INEP com detalhes em planilhas sobre a situação de todas as escolas municipais, estaduais e federais nas edições do IDEB de 2005, 2007, 2009 e 2011, apresentando especificamente: a) a média de desempenho dos alunos nos exames padronizados de Português e Matemática (Prova Brasil); b) a taxa referente ao fluxo escolar; c) o IDEB medido; d) o IDEB projetado. A planilha atualizada com a edição de 2013 encontra-se disponível para download ${ }^{3}$ no Portal do INEP.

Do arquivo citado foram extraídos apenas os dados das escolas públicas municipais de Fortaleza, considerando as edições do IDEB de 2005, 2007, 2009 e 2011. Os dados referentes à edição de 2013 não entraram especificamente nesse critério de seleção.

\footnotetext{
${ }^{1}$ Conforme Instituto Unibanco. Anuário da Educação de Fortaleza, 2012-2013. Disponível em: <http://www.institutounibanco.org.br/blog/2013/08/12/conheca-o-anuario-brasileiro-da-educacao-basica-2013 $>$. Acesso em: 02 out. 2015.

${ }^{2}$ Conforme INEP. Microdados do Censo Escolar. Disponível em: <http://inep.gov.br/web/guest/microdados $>$.

${ }^{3}$ Conforme INEP. Cenário Educacional. Disponível em: <http://portal.inep.gov.br/web/guest/cenario-

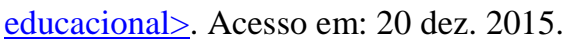

\section{POLÊM!CA $\mid$ LABORË}

Polêmica - Revista Eletrônica da Uerj - Rua São Francisco Xavier, 524, $1^{\circ}$ andar bloco D, sl.1001 • Tels.: +55 21 2334-4088 / 4087 • http://www.e-publicacoes.uerj.br/index.php/polemica/index http://www.labore.uerj.br • laboreuerj@yahoo.com.br 
Para selecionar as escolas investigadas, deu-se ênfase, inicialmente, ao IDEB de cada unidade pública municipal de Fortaleza. Os procedimentos realizados para a seleção dos casos/escolas seguiram os critérios detalhados abaixo:

$\checkmark$ Critério de Corte 1: Do arquivo citado, filtrou-se as escolas municipais de Fortaleza que participaram da Prova Brasil nas edições de 2005 a 2011. Obteve-se 234 escolas;

$\checkmark$ Critério de Corte 2: Das 234 unidades escolares, filtrou-se as que apresentavam IDEB para os anos iniciais ( $4^{\circ} / 5^{\circ}$ anos) e finais $\left(6^{\circ} / 9^{\circ}\right.$ anos) do Ensino Fundamental. Por este critério, obteve-se 113 unidades escolares. Neste corte, observou-se que muitas escolas conseguiram evoluir ininterruptamente as metas pré-definidas pelo INEP para as turmas de $4^{\circ} / 5^{\circ}$ ano. Mas o mesmo não acontecia para as turmas de $8^{\circ} / 9^{\circ}$ ano;

$\checkmark$ Critério de Corte 3: Das 113 escolas identificadas anteriormente, filtrou-se somente as que conseguiram atingir e/ou superar continuamente as metas projetadas pelo INEP nas duas etapas do Ensino Fundamental $\left(4^{\circ} / 5^{\circ}\right.$ e $8 / 9^{\circ}$ anos). Constatou-se que apenas sete unidades conseguiram evoluir seu índice consecutivamente.

$\checkmark$ Critério de Corte 4: Das sete escolas, selecionou-se três para o desenvolvimento da pesquisa, definindo-se como último critério as que tiveram o maior número de matrículas no ano de 2013.

Para resguardar a identificação das escolas e dos sujeitos que participaram da pesquisa, as unidades selecionadas foram identificadas nesse trabalho como: Escola A, Escola B e Escola C, conforme apresentadas na Tabela I, com a quantidade de alunos matriculados no ano letivo de 2013, seus respectivos índices observados nas edições de 2007, 2009, 2011 e 2013. Ao lado estão suas respectivas metas projetadas.

Tabela - 1: Escolas selecionadas com seus respectivos IDEB observados e projetados para o Ensino Fundamental

\begin{tabular}{|c|c|c|c|c|c|c|c|c|c|c|c|}
\hline \multirow{10}{*}{ 资 } & \multirow{2}{*}{\multicolumn{2}{|c|}{$\begin{array}{c}\text { NO ME DA } \\
\text { ESCOLA }\end{array}$}} & \multirow{3}{*}{$\begin{array}{c}\text { QUANTIDADE DE } \\
\text { MATRÍCULAS EM } 2013 \\
\text { De } 1^{\circ} \text { ao } 5^{\circ} \text { ano }\end{array}$} & \multicolumn{8}{|c|}{ IDEB - RESULTADOS E METAS } \\
\hline & & & & \multicolumn{4}{|c|}{ IDEB Observado } & \multicolumn{4}{|c|}{ Metas Projetadas } \\
\hline & $\underline{2}$ & & & 2007 & 2009 & 2011 & 2013 & 2007 & 2009 & 2011 & 2013 \\
\hline & 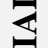 & Escola A & 245 & 3.3 & 4.6 & 4.8 & 5.3 & 3.1 & 3.4 & 3.9 & 4.1 \\
\hline & $\underline{\sigma}$ & Escola B & 281 & 3.4 & 3.8 & 4.3 & 4.4 & 3.2 & 3.5 & 3.9 & 4.2 \\
\hline & 台 & Escola C & 372 & 3.4 & 3.8 & 4.3 & 4.5 & 3.2 & 3.6 & 4.0 & 4.3 \\
\hline & & & De $6^{\circ}$ ao $9^{\circ}$ ano & 2007 & 2009 & 2011 & 2013 & 2007 & 2009 & 2011 & 2013 \\
\hline & $\frac{\Omega}{2}$ & Escola A & 321 & 3.1 & 3.9 & 4.0 & 3.9 & 2.5 & 2.6 & 2.9 & 2.5 \\
\hline & 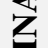 & Escola B & 355 & 3.4 & 3.4 & 3.9 & 3.4 & 2.4 & 2.6 & 2.9 & 3.2 \\
\hline & 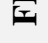 & Escola C & 519 & 3.1 & 3.7 & 4.4 & 4.1 & 2.4 & 2.7 & 3.1 & 3.6 \\
\hline
\end{tabular}

Fonte: COPLAN/SME; Portal do INEP. Disponível em: <http://ideb.inep.gov.br/resultado>.

\section{POLÊM!CA | LABORË}

Polêmica - Revista Eletrônica da Uerj - Rua São Francisco Xavier, 524, $1^{\circ}$ andar bloco D, sl.1001 • Tels.: +55 21 2334-4088 / 4087 • http://www.e-publicacoes.uerj.br/index.php/polemica/index http://www.labore.uerj.br • laboreuerj@yahoo.com.br 
A partir dos critérios definidos para seleção das escolas, buscou-se localizá-las geograficamente. Foi neste momento que se constatou um dado importante: as três estão situadas em diferentes áreas, onde se podem verificar os menores indicadores sociais da capital cearense, dentre eles o Índice de Desenvolvimento Humano por bairro (IDH-B). (IPECE, 2012).

A classificação do IDH-B, assim como o Índice de Desenvolvimento Humano Municipal (IDH-M), varia em uma escala de 0 a 1. Quanto mais próximo de 1, maior o grau de desenvolvimento humano; e quanto mais próximo de zero, menor o grau de desenvolvimento humano. (IPECE, 2012). O último IDH-M de Fortaleza, avaliado em 2013 foi 0,754 de acordo com o Programa das Nações Unidas para o Desenvolvimento (PNUD, 2013).

A Tabela II, a seguir, apresenta o nome do bairro onde cada escola pesquisada está situada e o respectivo Índice de Desenvolvimento Humano do Bairro (IDH-B).

Tabela - 2: Localização das escolas selecionadas para a pesquisa com seu respectivo número de matrículas no ano de 2013, e IDH-B

\begin{tabular}{c|c|c}
\hline NOME DA ESCOLA & BAIRRO & IDH DO BAIRRO \\
\hline Escola A & Barra do Ceará & 0,215 (baixo) \\
\hline Escola B & Siqueira & 0,148 (baixo) \\
\hline Escola C & Jangurussu & 0,172 (baixo) \\
\hline
\end{tabular}

Fonte: COPLAN/SME; SDE (FORTALEZA, 2014).

O método utilizado para apresentar a situação de desenvolvimento humano nos bairros levou em conta as seguintes dimensões: educação (alfabetização e taxa de matrícula), longevidade (esperança de vida ao nascer) e renda (PIB per capita) (FORTALEZA, 2015).

Conhecer como as unidades escolares pesquisadas utilizaram os resultados do IDEB torna o presente estudo relevante, uma vez que os maiores índices na Rede Municipal de Ensino de Fortaleza, nas edições de 2007 a 2013, foram obtidos por escolas localizadas em bairros com os menores IDH-B dessa cidade.

\section{O recorte empírico e estratégias de pesquisa}

Em relação aos métodos de pesquisas, a proposta para o desenvolvimento desse estudo passou pelas três fases, sendo: $1^{\circ}$ ) a fase exploratória, na qual se amadurece o objeto de estudo e se delimita o problema de investigação; $2^{\circ}$ ) a fase de coleta de dados, em que se recolhem

\section{POLÊM!CA $\mid$ LABORE}

Polêmica - Revista Eletrônica da Uerj - Rua São Francisco Xavier, 524, $1^{\circ}$ andar bloco D, sl.1001 • Tels.: +55 21 2334-4088 / 4087 • http://www.e-publicacoes.uerj.br/index.php/polemica/index http://www.labore.uerj.br • laboreuerj@yahoo.com.br 
informações que respondam ao problema; e $3^{\circ}$ ) a fase de análise de dados, na qual se faz o tratamento, por inferências e interpretações, dos dados coletados (MINAYO, 2001).

A pesquisa é do tipo exploratória com abordagem qualitativa. Na seleção da amostragem foram utilizados dados quantitativos, para a delimitação dos casos analisados. Dada a quantidade de escolas e de sujeitos selecionados, optou-se pelo uso do método de Estudo de Casos Múltiplos.

A partir das questões levantadas e do referencial estudado, a pesquisa teve como propósito o estudo dos fatores expostos na Figura 1:

Figura - 1: Relação dos fatores estudados na pesquisa

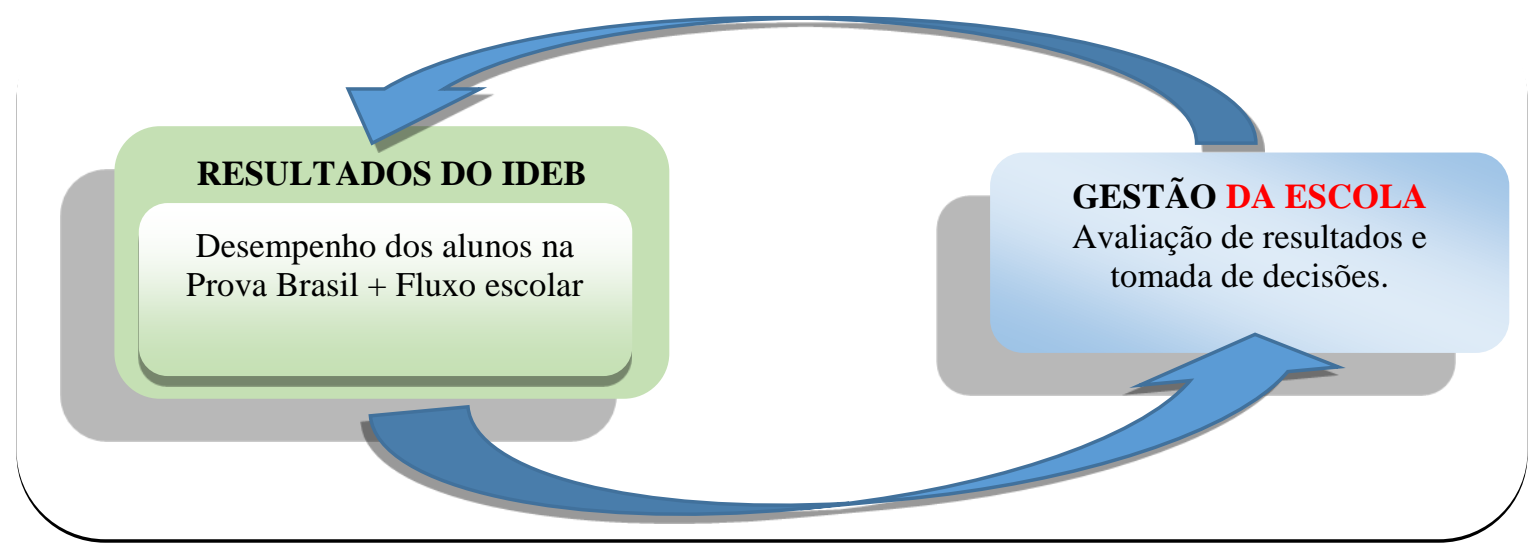

Fonte: $\mathrm{O}$ autor.

“Resultados do IDEB” se constitui como primeira categoria de pesquisa, a qual está relacionada ao desempenho das escolas investigadas quanto à evolução continuada dos seus resultados em relação as suas metas pré-definidas pelo INEP. Sobre esse aspecto, buscou-se observar as médias de desempenho dos estudantes nas avaliações padronizadas (SAEB e PROVA BRASIL) e taxa média de aprovação escolar (Censo Escolar) em cada escola, considerando as edições de 2005, 2007, 2009 e 2011. Os dados de 2013 também foram observados, embora não tenham sido utilizados como critério para seleção das unidades pesquisadas.

Gestão da escola é a segunda categoria de pesquisa e diz respeito à gestão escolar no âmbito da organização e gestão da escola, ou seja, como a equipe se articula em suas ações de gestão para a realização dos objetivos e metas do sistema educativo. A definição dessa categoria partiu da realidade encontrada nas escolas investigadas, considerando-se o conjunto de

\section{POLÊM!CA | LABORE}

Polêmica - Revista Eletrônica da Uerj - Rua São Francisco Xavier, 524, $1^{\circ}$ andar bloco D, sl.1001 • Tels.: +55 21 2334-4088 / 4087 • http://www.e-publicacoes.uerj.br/index.php/polemica/index http://www.labore.uerj.br • laboreuerj@yahoo.com.br 
profissionais que formava a "equipe de gestão da escola" composta, de modo geral, pelo: diretor, vice-diretor, coordenador pedagógico e/ou supervisor escolar e orientador educacional (LIBÂNEO, OLIVEIRA, TOSCHI, 2012).

Para a análise da categoria 'gestão da escola', buscou-se compreender como os dados que compõem o resultado do IDEB são apropriados e utilizados no processo de gestão de três escolas municipais de Fortaleza, a partir da perspectiva da equipe de gestão que atuou no período de 2005 a 2013.

Os termos "apropriações e usos" foram empregados no sentido de se compreender ações de gestão, planejadas na intenção de se melhorar continuamente os resultados do IDEB.

Os dados utilizados para a pesquisa de campo foram coletados por meio de análise documental e entrevistas semiestruturadas, no período entre abril de 2014 a janeiro de 2015, com nove profissionais, dos quais oito integraram a equipe de gestão das três escolas no período 2005 a 2013; e um foi gestor Secretaria Municipal de Educação, durante o período de 2007 a 2013.

Para a primeira etapa de coleta de dados, foram obtidos diversos documentos oficiais que dão sustentabilidade à política educacional brasileira e que direcionam a gestão da educação do município de Fortaleza, considerando as que estruturam a organização e o planejamento administrativo desse município, tais como: Plano Municipal de Educação, Diretrizes Curriculares para o Ensino Municipal Público de Fortaleza, portarias e decretos que disciplinam as ações de gestão.

No âmbito das escolas, foram coletados os documentos: Projeto Político-Pedagógico, plano de gestão, registros de projetos pedagógicos desenvolvidos, relatórios de turmas, atas de reuniões, dentre outros que subsidiaram a pesquisa. Esse material foi analisado no sentido de se compreender e se interpretar a realidade investigada, considerando que o foco desses documentos tende a fundamentar a política educacional vivenciada no dia a dia das escolas, além de evidenciar elementos que auxiliam na descrição do objeto de estudo.

A segunda etapa para a coleta de dados se deu, predominantemente, por meio de entrevistas individuais junto aos profissionais que participaram desse estudo, utilizando-se roteiros com perguntas abertas relativas ao tema da pesquisa.

A partir do material coletado para estudo, foi possível identificar um conjunto de ações desenvolvidas pela equipe de gestão das escolas investigadas, considerando as mudanças no

\section{POLÊM!CA $\mid$ LABORE}

Polêmica - Revista Eletrônica da Uerj - Rua São Francisco Xavier, 524, $1^{\circ}$ andar bloco D, sl.1001 • Tels.: +55 21 2334-4088 / 4087 • http://www.e-publicacoes.uerj.br/index.php/polemica/index http://www.labore.uerj.br • laboreuerj@yahoo.com.br 
cenário educacional brasileiro, nos últimos anos, que tem gerado desafios para os sistemas de ensino e escolas.

\section{O IDEB e desafios para a gestão dos sistemas de ensino e escolas}

Os testes cognitivos do SAEB, elaborados com base em matrizes de referência, levam à definição do que deve ser considerado fundamental em termos de aprendizagem escolar e, portanto, do que todos os alunos deveriam saber e ser capazes de fazer, ao final de determinados ciclos de escolarização.

Para Fernandes e Gremaud (2009), as limitações do desenho amostral do SAEB motivaram sua reformulação em 2005, que modificou seu caráter histórico de exame amostral, ao ampliar o conteúdo informacional da avaliação e suas consequências sobre as escolas, agregando a perspectiva diagnóstica à noção de responsabilização. A partir da referida portaria, o SAEB passou a ser composto por duas avaliações externas em larga escala: a Avaliação Nacional da Educação Básica (ANEB), que manteve basicamente as mesmas características da avaliação amostral realizada até 2003; a Avaliação Nacional do Rendimento Escolar (ANRESC), conhecida como Prova Brasil, aplicada aos alunos de $5^{\circ}$ e $9^{\circ}$ anos do Ensino Fundamental de escolas públicas de área rural e urbana que tenham no mínimo 20 alunos matriculados nos anos avaliados. (BRASIL, 2005).

Na edição de 2013, o SAEB incorporou ao seu processo a Avaliação Nacional da Alfabetização (ANA), com base na Portaria n 482, de 7 de junho de 2013. Trata-se de uma avaliação censitária para alunos do $3^{\circ}$ ano do Ensino Fundamental das escolas públicas, com o objetivo principal de avaliar os níveis de alfabetização e letramento em Língua Portuguesa e alfabetização Matemática, conforme previsto no Pacto Nacional pela Alfabetização na Idade Certa- PNAIC.

A Prova Brasil ocorre desde 2005, a cada dois anos, quando são aplicados testes cognitivos de Língua Portuguesa e de Matemática, além de questionários contextuais aos alunos, professores e diretores das escolas avaliadas, com o intuito de identificar: o nível socioeconômico dos alunos; hábitos de estudos; perfil e condições de trabalho dos docentes e diretores; tipo e organização da escola; projeto pedagógico, dentre outros aspectos relevantes para o desenvolvimento do ensino e da aprendizagem.

\section{POLÊM!CA $\mid$ LABORE}

Polêmica - Revista Eletrônica da Uerj - Rua São Francisco Xavier, 524, $1^{\circ}$ andar bloco D, sl.1001 • Tels.: +55 21 2334-4088 / 4087 • http://www.e-publicacoes.uerj.br/index.php/polemica/index http://www.labore.uerj.br • laboreuerj@yahoo.com.br 
Diante das mudanças que vem ocorrendo, durante as últimas três décadas, no cenário educacional brasileiro, observa-se que a sistemática de avaliação passou gradativamente a integrar políticas e práticas governamentais, constituindo-se, hoje, em uma importante estratégia de regulação da educação básica no país (FREITAS, 2007).

A reformulação do SAEB, em 2005, associada ao Plano de Metas Compromisso Todos pela Educação, em 2007, provocou mudanças no cenário educacional brasileiro, ao trazerem em seu cerne a necessidade de uma educação de qualidade para todos, considerando a melhoria dos serviços prestados pelas escolas, que passaram a assumir maior responsabilidade, na promoção e êxito dos seus alunos. Isso tem respaldo no Decreto 6.094/2007, dispositivo que põe em vigência o Plano de Desenvolvimento da Educação (PDE).

No momento do lançamento do PDE, o Ministério da Educação lançou o IDEB pelo decreto citado, atrelando a esse índice as ações e programas que cobrem todos os níveis e modalidades de ensino. Buscando expor a percepção sistêmica da educação no PDE, Araújo, que estava como presidente do INEP em 2007, explica que:

Todo o PDE está ancorado justamente na criação do Índice de Desenvolvimento da Educação Brasileira - IDEB, que pondera os resultados do SAEB, da Prova Brasil e dos indicadores de desempenho captados pelo censo escolar (evasão, aprovação e reprovação). Cria um indicador que varia de zero a dez, desdobrável por estado e por município, por redes de ensino e agora por escola. A partir da construção do IDEB, o MEC vinculará o repasse de recursos oriundos do FNDE à assinatura de compromisso dos gestores municipais com determinadas metas de melhoria dos seus indicadores ao longo de determinado período (ARAÚJO, 2007, p. 1).

Nesse entendimento, o monitoramento do IDEB constitui-se como o principal referencial de qualidade a ser seguido pelas escolas públicas brasileiras, válido para mensurar objetivamente a qualidade de uma escola ou de um sistema educacional, a partir da combinação das médias de desempenho dos estudantes nas avaliações padronizadas (Prova Brasil) e taxa média de aprovação escolar (Censo Escolar), conforme Art. $3^{\circ}$ do Decreto 6.094/2007, que trata do Plano de Metas Compromisso Todos pela Educação.

Percebe-se, portanto, que a "gestão de resultados", mencionada no Decreto 6.094/2007, impõe que os administradores na gestão do ensino busquem, a partir das informações disponibilizadas pelo INEP, identificar e solucionar problemas existentes em cada escola. A perspectiva dessa política educacional, içada em um índice/resultado que pode variar numa escala de zero a dez, é que cada instância escolar evolua de forma a contribuir em conjunto,

\section{POLÊM!CA $\mid$ LABORE}

Polêmica - Revista Eletrônica da Uerj - Rua São Francisco Xavier, 524, $1^{\circ}$ andar bloco D, sl.1001 • Tels.: +55 21 2334-4088 / 4087 • http://www.e-publicacoes.uerj.br/index.php/polemica/index http://www.labore.uerj.br • laboreuerj@yahoo.com.br 
para que o Brasil atinja o nível educacional da média dos países considerados desenvolvidos. Em termos numéricos, isso significa progredir para um valor de referência igual a 6,0 (IDEB 6,0), até o ano 2021, quando “o Brasil completará 200 anos de sua independência” (HADDAD, 2008, p. 21).

A série histórica do IDEB iniciou em 2005, quando foram estabelecidas pelo INEP as metas bienais de qualidade a serem atingidas por todos os entes federativos. Como um fator inovador, a discriminação dos resultados é disponibilizada de forma desagregada do sistema de ensino, apresentada por estado, por município e por escola. Ressalta-se, ainda, a possibilidade de se conhecer os resultados de uma turma ou de um aluno, por meio dos $\operatorname{microdados}^{4}$ que são disponibilizados no portal do INEP.

Frente às possibilidades de as escolas e os sistemas de ensino buscarem conhecer melhor seus resultados, a discussão realizada neste artigo destaca a importância de as instituições superarem os problemas apontados, a partir dos próprios resultados obtidos nas avaliações externas. Emergem nesse contexto a necessidade de descrever o Sistema Permanente de Avaliação da Educação Básica (SPAECE), considerando que os achados da pesquisa realizada convergem para o uso dos resultados desse sistema de avaliação pelas escolas cearenses, embora esse não tenha sido o foco da pesquisa.

\section{O Sistema Permanente de Avaliação da Educação Básica do Ceará}

Em sintonia com uma preocupação nacional, as experiências da Secretaria de Educação do Estado do Ceará (SEDUC), após o primeiro ciclo de avaliações do SAEB, em 1990, se voltaram para a criação do Sistema de Avaliação do Rendimento Escolar, em 1992, financiado pelo Governo do Estado do Ceará, para alunos de $4^{\circ}$ e $8^{\circ}$ anos. Essa vertente da avaliação foi ampliada em 1996, o referido sistema se consolidou e passou a se chamar Sistema Permanente de Avaliação Básica do Ceará (SPAECE) (MAGALHÃES JÚNIOR, 2013).

Ao longo do tempo, o SPAECE ampliou sua abrangência, caracterizando-se, hoje, como avaliação externa censitária em larga escala, tendo como objetivo principal avaliar a qualidade do ensino oferecido nas escolas públicas do Estado do Ceará (municipais e estaduais), mediante

\footnotetext{
${ }^{4} \mathrm{O}$ download dos microdados da Prova Brasil, ANA, SAEB e Censo Escolar pode ser feito pelo site: http://portal.inep.gov.br/basica-levantamentos-acessar. Os dados do IDEB por unidade administrativa e por escola está disponível em: http://portal.inep.gov.br/web/portal-ideb/planilhas-para-download. Acessados em: 02 ago. 2016.
}

\section{POLÊM!CA $\mid$ LABORË}

Polêmica - Revista Eletrônica da Uerj - Rua São Francisco Xavier, 524, $1^{\circ}$ andar bloco D, sl.1001 • Tels.: +55 21 2334-4088 / 4087 • http://www.e-publicacoes.uerj.br/index.php/polemica/index http://www.labore.uerj.br • laboreuerj@yahoo.com.br 
o desempenho dos alunos nas disciplinas Língua Portuguesa e Matemática, nos finais do Ensino Fundamental e Médio.

Seguindo os moldes da Prova Brasil, o SPAECE avalia de forma censitária a alfabetização (SPAECE-Alfa ( $2^{\circ}$ ano); o Ensino Fundamental ( $5^{\circ}$ e $9^{\circ}$ anos) e o Ensino Médio $\left(1^{\circ}, 2^{\circ}\right.$ e $3^{\circ}$ anos $)$. A avaliação dos alunos da $2^{\circ}$ e $3^{\circ}$ anos do Ensino médio é realizada de forma amostral, com representatividade por escola.

O SPAECE-Alfa acontece todos os anos. As avaliações do $5^{\circ}$ e $9^{\circ}$ anos e do Ensino Médio acontecem de dois em dois anos, sendo aplicado nos anos em que não há a aplicação nacional. Isso indica que todos os anos as escolas cearenses passam por avaliações externas, ou seja, exames advindos dos governos: ora estadual (SPAECE), ora federal (SAEB/Prova Brasil).

Os testes padronizados do SPAECE, assim como a Prova Brasil, estão baseados em itens construídos, a partir de uma matriz de referência para avaliar o quanto os alunos estão próximos ou distantes da aprendizagem ou do desenvolvimento de competências e habilidades que se esperam para eles, ao fim de um determinado nível de ensino.

\section{Apropriações e usos de dados educacionais}

Para as observações sobre os dados coletados em documentos e entrevistas, pressupôsse que o cargo público exercido pelos membros da equipe de gestão das escolas "não permite que eles ignorem as políticas educacionais implementadas em suas escolas", já que esses profissionais precisam realizar uma leitura das demandas trazidas e, simultaneamente, oferecer uma resposta aos professores, aos pais, à comunidade e à administração central (BONAMINO; SOUSA, 2012)

Ao analisar como os dados do IDEB foram apropriados e utilizados para a gestão da educação pública municipal de Fortaleza, foi possível constatar que não havia, em nível de rede, ações planejadas na intenção de se melhorar seus indicadores, a partir dos resultados disponibilizados pelo INEP. No entanto, foram identificadas em documentos, três ações para o primeiro seguimento do Ensino Fundamental, que passaram a ocorrer a partir de 2010: 1) reuniões do gestor da pasta da educação com a equipe de gestão das escolas avaliadas pelo INEP, nas ocasiões de divulgação dos resultados do IDEB. O objetivo era apresentar, por meio de um ranking, as escolas que tiveram bom desempenho e ressaltar a importância do trabalho desenvolvido pela unidade escolar em destaque; 2) avaliação diagnóstica realizada pela SME,

\section{POLÊM!CA $\mid$ LABORE}

Polêmica - Revista Eletrônica da Uerj - Rua São Francisco Xavier, 524, $1^{\circ}$ andar 
que de certa forma preparava/prepara para a Prova Brasil, a qual estava limitada ao primeiro seguimento do Ensino Fundamental; 3) desenvolvimento do programa do Governo do Estado do Ceará para alfabetizar os alunos da rede pública de ensino até o final do segundo ano do Ensino Fundamental (Programa Alfabetização na Idade Certa - PAIC).

Não foram identificadas ações da SME voltadas ao segundo seguimento do Ensino Fundamental e, na busca de registros sobre o trabalho desenvolvido que pudessem evidenciar as informações coletadas em entrevistas, constatou-se a ausência de políticas municipais que dessem suporte e orientassem a leitura e o uso dos dados das avaliações externas pelas escolas, no período analisado.

A situação apresentada indica que o primeiro Plano Municipal de Educação de Fortaleza (PME), constituído como instrumento de planejamento para os gestores da rede municipal, não foi suficiente para alavancar as metas e as estratégias de ação para o desenvolvimento da educação de Fortaleza. No que se refere à avaliação da aprendizagem, dentro dos objetivos e metas/ações do PME, tem-se como perspectiva:

[...] assegurar a elevação progressiva de desempenho em todo o sistema de ensino por meio de um programa de monitoramento e correção dos indicadores de desempenho pela Prova Brasil, do SAEB, do SPAECE e do sistema de avaliação municipal que venha a ser desenvolvido (FORTALEZA, 2009).

O trecho acima se constitui como um grande desafio para o PME da década seguinte (2015-2025), considerando o fato de que a maioria das escolas que atuam com os anos finais não conseguiu evoluir seus indicadores, situação problematizada no recorte empírico desta pesquisa.

A Proposta Pedagógica da rede (FORTALEZA 2011a; 2011b) era (ou ainda é) um dos documentos que configura as intencionalidades e as linhas mais gerais da Secretaria de Educação. No entanto, ainda assim, não foram encontradas referências ao alcance de metas educacionais ou mesmo estratégias que indicassem como as escolas poderiam superar suas dificuldades para melhorar os resultados dos alunos apresentados nas avaliações externas.

No âmbito das escolas investigadas, os profissionais que compunham a equipe de gestão, dentro do recorte temporal eram: diretor e vice-diretor; secretário Escolar; supervisor escolar, dois coordenadores pedagógicos e orientador educacional. Mas, no período investigado, apenas na Escola $\mathrm{C}$ havia o orientador educacional e, na Escola A, só havia um coordenador pedagógico.

\section{POLÊM!CA | LABORE}

Polêmica - Revista Eletrônica da Uerj - Rua São Francisco Xavier, $524,1^{\circ}$ andar bloco D, sl.1001 • Tels.: +55 21 2334-4088 / 4087 • http://www.e-publicacoes.uerj.br/index.php/polemica/index http://www.labore.uerj.br • laboreuerj@yahoo.com.br 
Para atingir as metas projetadas pelo INEP, em relação ao IDEB, as três unidades escolares se organizaram de formas distintas, embora tenham apresentado ações semelhantes com o intuito de melhorar seus indicadores (fluxo escolar e proficiência dos estudantes em Português e Matemática).

Para reduzir as taxas de reprovação, desistência e abandono, ao tempo em que se melhorava a proficiência dos estudantes nas avaliações externas, a equipe de gestão da Escola A dedicou-se a identificar dificuldades que os estudantes enfrentavam em relação aos conteúdos curriculares, assiduidade ou comportamento, que prejudicassem o trabalho acadêmico. Esse trabalho, iniciado em 2007, foi realizado com base em um projeto próprio intitulado "Padrinhos de Turma", que tinha como objetivo principal minimizar os graves problemas que afetavam o trabalho escolar, tais como: "defasagem idade/série, reprovação, abandono dos estudos, movimento de gangues, violência doméstica, trabalho infantil, uso de entorpecentes de pais e filhos e promiscuidade". De acordo com os relatórios desenvolvidos de 2007 a 2012, elaborados com base neste projeto, cada membro da equipe se responsabilizava pelo acompanhamento dos alunos de uma determinada quantidade de turmas, monitorando a frequência dos estudantes e seu desempenho junto aos professores das disciplinas de Português e Matemática. O conjunto de ações desenvolvidas não mantinha relação direta com o PPP de 2005 e sua atualização de 2010 (Escola A, Projeto Padrinhos de Turma, p. 2).

Na Escola B, a proposta do PPP de 2005 e sua atualização de 2010 partiram de orientações dadas por uma empresa de serviços de assessoria pedagógica contratada pela própria escola, pelo período de novembro de 2007 a outubro de 2008. Este documento explicitava a necessidade de se reconhecer a situação de aprendizagem de cada aluno, suas necessidades, interesses, desempenho e dificuldades, para se pensar na metodologia a ser utilizada, na organização da sala de aula e nas atitudes a adotar, para que fosse possível atingir o objetivo da escola B: a aprendizagem do aluno. O plano de ação indicava o desenvolvimento de projetos temáticos envolvendo os conteúdos curriculares de todas as áreas integrados ao uso de jogos colaborativos e competitivos em todos os anos. Mas, ao analisar os relatórios de atividade dos projetos relativos aos anos de 2010 a 2012, foi possível constatar que o foco deste trabalho estava centrado no desenvolvimento das habilidades avaliadas na Prova Brasil de Português e Matemática, envolvendo unicamente $4^{\circ}, 5^{\circ}, 8^{\circ}$ e $9^{\circ}$ anos. Não foram identificadas ações específicas voltadas para a redução das taxas de desistência e abandono.

\section{POLÊM!CA | LABORE}

Polêmica - Revista Eletrônica da Uerj - Rua São Francisco Xavier, $524,1^{\circ}$ andar bloco D, sl.1001 • Tels.: +55 21 2334-4088/4087 • http://www.e-publicacoes.uerj.br/index.php/polemica/index http://www.labore.uerj.br • laboreuerj@yahoo.com.br 
A Escola C apresentou o PPP atualizado em 2010 junto com os relatórios das ações desenvolvidas nos anos de 2010 a 2012. Não foram encontrados documentos específicos que evidenciassem o trabalho dos gestores em relação à melhoria das taxas de fluxo escolar e desempenho dos alunos na Prova Brasil.

Dentre as principais estratégias dos gestores das três escolas investigadas, que possivelmente influenciaram a evolução das metas do IDEB, estavam: 1) Reuniões periódicas da equipe de gestão para tomada de decisões em relação às dificuldades enfrentadas pelos professores e a escola; 2) Participação dos gestores nos momentos de planejamento dos professores; 3) Registro dos itens da prova do SPAECE em que os alunos apresentaram mais dificuldades; 4) Mapeamento das habilidades dos alunos avaliadas pelo SPAECE que devem ser mais trabalhadas pelos professores de Português e Matemática; 5) Teste de sondagem para os estudantes com base na matriz de referência da Prova Brasil e SPAECE; 6) Triagem de alunos por nível e área de ensino para aulas de reforço no contra turno; 7) Monitoramento do relatório dos professores em relação às dificuldades dos alunos em Português e Matemática; 8) Monitoramento do nível dos estudantes nas escalas de aprendizagem dos alunos no SPAECE; 9) Realização de simulados para os exames externos, com base nas matrizes de referência do SPAECE e Prova Brasil; 10) Busca pelos pais (ou responsáveis) na participação da vida escolar dos alunos que apresentam dificuldades; 11) Investimento de tempo pessoal da equipe de gestão com trabalhos da escola; 12) manutenção da infraestrutura da escola; 13) Boa relação de trabalho/parceria com os profissionais, quanto aos planos e metas de melhoria dos resultados; 14) diálogo com a comunidade e conselho escolar atuante.

Ao compreender como os dados do IDEB foram apropriados e utilizados pela equipe de gestão das três escolas investigadas, observou-se que: 1) O formato em que o INEP apresenta os resultados às escolas não atende às expectativas dos gestores, que relataram que os dados que compõem o IDEB da escola não apontam problemas específicos a serem gerenciados; 2) Os resultados demoram cerca de um ano para serem disponibilizados; 3) Os dados relativos ao fluxo escolar são complexos e não expõem as fragilidades da escola; 4) Os resultados de proficiência não discriminam a situação por aluno ou turma. Quanto aos microdados da Prova Brasil, disponibilizados pelo INEP, verificou-se o desconhecimento dos gestores em relação ao conteúdo e possibilidades de uso.

\section{POLÊM!CA | LABORE}

Polêmica - Revista Eletrônica da Uerj - Rua São Francisco Xavier, 524, $1^{\circ}$ andar bloco D, sl.1001 • Tels.: +55 21 2334-4088 / 4087 • http://www.e-publicacoes.uerj.br/index.php/polemica/index http://www.labore.uerj.br • laboreuerj@yahoo.com.br 
Ao elucidar as principais ações/decisões adotadas pelos gestores, que resultaram na evolução das metas do IDEB, ficou clara a preferência destes profissionais pela utilização dos resultados das avaliações, o SPAECE. Esta preferência foi justifica pela estrutura diferenciada do SPAECE, em relação à Prova Brasil, pois: 1) Expõe os dados para as escolas de forma detalhada, permitindo que os gestores e professores conheçam a realidade das turmas, inclusive individualmente dos estudantes, por meio de boletins; 2) Indica aspectos que devem ser melhorados pela escola em relação ao ensino ou a aprendizagem dos alunos; 3) Apresenta os resultados de forma simplificada, detalhada e em menos tempo que o INEP.

O contexto revelou que o esforço das equipes de gestão em melhorar a aprendizagem dos alunos nos conteúdos de Português e Matemática era subsidiado de fato com os resultados do SPAECE, e não a partir dos dados fornecidos pelo INEP. Dava-se prioridade às atividades de leitura e escrita por considerarem que eram as maiores fragilidades dos alunos do $2^{\circ}, 5^{\circ}$ e $9^{\circ}$ anos, segundo o SPAECE.

Analisando os números relativos à aprovação, reprovação e abandono, no período de 2007 a 2013, coletados no Censo Escolar, observou-se que o trabalho das três escolas teve impulso maior na melhoria da proficiência (nível aprendizagem na Prova Brasil) do que nas taxas de aprovação dos estudantes nas escolas (fluxo escolar).

Sobre o fluxo escolar, os gestores das escolas afirmaram que até o ano 2005 ou 2007 não havia o que eles consideravam "preocupação" com a frequência dos alunos, inclusive nos dias de exame externo. Para esses profissionais, a reprovação tem ocorrido mais pela evasão e abandono dos alunos do que pela falta de conhecimento e condições de serem aprovados nas disciplinas curriculares.

Quanto à taxa de troca entre o fluxo e proficiência, presente na estrutura do IDEB, Fernandes (2007, p.16) afirma que este é o propósito do índice, pois “o indicador incentiva as unidades escolares (escolas e redes de ensino) a operarem com baixas taxas de reprovação, a não ser que repetências tenham um forte impacto positivo no aprendizado dos alunos (repetentes ou não)".

Observando como as escolas investigadas conseguiram evoluir seus resultados no IDEB continuamente, identificou-se ações de gestão de acompanhamento aos alunos e o fortalecimento da dimensão pedagógica, no entanto, constatou-se uma redução do currículo escolar e a supervalorização da matriz da Prova Brasil. Verificou-se também que o IDEB dos

\section{POLÊM!CA $\mid$ LABORE}

Polêmica - Revista Eletrônica da Uerj - Rua São Francisco Xavier, $524,1^{\circ}$ andar bloco D, sl.1001 • Tels.: +55 21 2334-4088/4087 • http://www.e-publicacoes.uerj.br/index.php/polemica/index http://www.labore.uerj.br • laboreuerj@yahoo.com.br 
anos iniciais se apresenta superior ao dos anos finais, ficando a dúvida sobre o esforço estar concentrado com prioridade nos anos iniciais.

Concluiu-se, portanto, que a avaliação externa do Governo do Estado do Ceará, inspirado no sistema de avaliação nacional, tem subsidiado o trabalho da equipe de gestão e dos professores numa tentativa de alinhamento com a rede. Contudo, pode-se afirmar que o IDEB, oficialmente, é o único indicador estatístico que permite o monitoramento, em termos de diagnósticos e norteamentos de ações dos sistemas de ensino do País, capaz de aferir o que foi definido nacionalmente como qualidade.

Diante das análises apresentadas, considera-se que a avaliação aplicada ao Ensino Fundamental e outras modalidades de ensino só poderá ser apreendida na sua totalidade se forem levados em conta não somente os resultados, mas também os processos (caminhos percorridos - ações, métodos, procedimentos, técnicas).

Neste entendimento, o presente estudo evidencia a necessidade de que gestores e professores busquem conhecer os resultados de sua escola nas avaliações externas para que possam utilizá-los como insumos estratégicos essenciais para o desenvolvimento do processo educativo em sua unidade escolar, pois "avaliar só para constatar uma realidade não é avaliar; é medir, é levantar dados. E dados são úteis quando se convergem em informações" (PESTANA, 2007, p. 62).

\section{Considerações finais}

A leitura dos resultados das avaliações externas, sejam elas do Governo Federal ou Estadual, é uma tarefa que vai além da apropriação dos dados pelos docentes, gestores escolares e municipais, pois exige o conhecimento sobre o significado dos instrumentos utilizados em larga escala.

No âmbito das escolas investigadas, a pesquisa mostrou a necessidade de que docentes e gestores percebam a relação entre as ações pedagógicas e de gestão que são implementadas na escola, com os resultados alcançados nas avaliações externas. A perspectiva é traçar um caminho para se preparar planos de ação e intervenção comprometidos com a realidade da unidade escolar.

Em nível de rede, o estudo apontou para a necessidade de que a gestão municipal e a estadual busquem garantir mais oportunidades para que os gestores e professores possam

\section{POLÊM!CA $\mid$ LABORE}

Polêmica - Revista Eletrônica da Uerj - Rua São Francisco Xavier, 524, $1^{\circ}$ andar 
conhecer e compreender as políticas de avaliação externa, considerando-se a necessidade de se produzir e desenvolver projeto pedagógico consistente, articulado e partindo dos próprios resultados da escola, como forma de (re)orientar suas práticas pedagógicas. Uma alternativa, neste sentido, seria a implementação de programas de formação de docentes que auxiliassem na compreensão e na utilização dos resultados das avaliações externas e demais dados educacionais, possibilitando sua análise estratégica com vistas à tomada de decisão.

A perspectiva é disseminar a prática de uso dos próprios resultados na escola para se buscar compreender o que tem gerado os problemas identificados por essas avaliações e atender demandas que parecem ser comuns às escolas. Há também que se investir na disponibilização destes dados em tempo adequado, pois no que se refere aos resultados obtidos nas avaliações do Governo Federal, o acesso pelos agentes escolares costuma demorar cerca de um ano.

Essa pesquisa almeja contribuir com o avanço no debate sobre as apropriações e usos dos dados das avaliações externas na comunidade acadêmica, nas escolas e em um público externo a ela (outras Secretarias de Educação, escolas, associação de pais e mestres), em favor da melhoria da qualidade da educação básica no país.

\section{Referências}

ARAÚJO, L. Os fios condutores do PDE são antigos. Jornal de Políticas Educacionais, n. 2, p. 24-31, set. 2007. Disponível em: 〈http://www.jpe.ufpr.br/n2_3.pdf>. Acesso em: 12 dez. 2015.

BONAMINO, Alicia; SOUSA, Sandra Zákia. Três gerações de avaliação da educação básica no Brasil: interfaces com o currículo da/na escola. Revista Educação e Pesquisa, São Paulo, v. 38, n. 2, p. 373-388, abr./jun. 2012. Disponível em: 〈http://www.scielo.br/pdf/ep/v38n2/aopep633.pdf〉. Acesso em: 20 dez. 2015.

BRASIL. Casa Civil. Lei de Diretrizes e Bases da Educação Nacional. Lei n ${ }^{\circ} 9.394$ de 20 de dezembro de 1996. Disponível em: <http://www.planalto.gov.br/ccivil_03/Leis/L9394.htm>. Acesso em: 12 jun. 2018

Plano de Metas Compromisso Todos pela Educação. Decreto n ${ }^{\circ}$ 6.094. Disponível em:

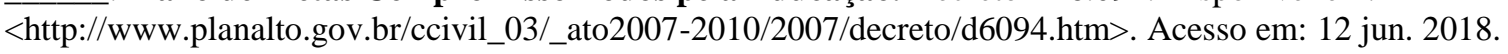

BRASIL, IBGE. Sinopse do Censo Demográfico 2010. Rio de Janeiro: IBGE, 2011. 265p. ISBN: 9788524041877 (meio impresso). Disponível em: <https://ww2.ibge.gov.br/home/estatistica/populacao/censo2010/sinopse/default_sinopse.shtm>. Acesso em: 20 dez. 2015 .

Censo 2010. Disponível em: <https://censo2010.ibge.gov.br/index.php〉. Acesso em: 12 dez. 2015.

BRASIL, INEP. Microdados do Censo Escolar. Disponível em: <http://inep.gov.br/web/guest/microdados>. Acesso em: 22 dez. 2015

\section{POLÊM!CA $\mid$ LABORE}

Polêmica - Revista Eletrônica da Uerj - Rua São Francisco Xavier, 524, $1^{\circ}$ andar bloco D, sl.1001 • Tels.: +55 21 2334-4088 / 4087 • http://www.e-publicacoes.uerj.br/index.php/polemica/index http://www.labore.uerj.br • laboreuerj@yahoo.com.br 
Resultados e resumos do Censo Escolar. Disponível em: <http://inep.gov.br/resultados-e-resumos〉. Acesso em: 22 dez. 2015.

Cenário Educacional. Disponível em: <http://portal.inep.gov.br/web/guest/cenario-educacional>. Acesso em: 22 dez. 2015.

BRASIL. MEC. Portaria nº 931 de 21 de março de 2005. Diário Oficial da União, Brasília, DF, n. 55, 22 mar. 2005. Seção 1, p. 17. Disponível em:

<http://download.inep.gov.br/educacao_basica/prova_brasil_saeb/legislacao/Portaria931_NovoSaeb.pdf>. Acesso em: 31 mai. 2017.

Portaria no 482, de 7 de junho de 2013. Dispõe sobre o Sistema de Avaliação da Educação Básica SAEB. Diário Oficial da União, Brasília, DF, n. 109, p. 17, 10 jun. 2013. Seção 1, p. 17. Disponível em: <http://download.inep.gov.br/educacao_basica/prova_brasil_saeb/legislacao/2013/portaria_n_482_07062013_m ec_inep_saeb.pdf>. Acesso em: 31 mai. 2017.

Portaria n 1.795 , de 27 de dezembro de 1994. Cria o Sistema Nacional de Avaliação da Educação Básica. Diário Oficial da União, Brasília, DF, seção 1, n. 246, p. 20.767-20.768, 28 dez. 1994.

CEARÁ. Secretaria da Educação Básica. Coordenadoria de Planejamento e Política Educacional. Núcleo de Pesquisa e Avaliação Educacional. SPAECE-NET: os novos caminhos da avaliação educacional - Relatório Geral - 2001. Fortaleza: SEDUC.

Programa Alfabetização na Idade Certa - PAIC. Histórico, objetivos e eixos do programa. Disponível em: <http://www.paic.seduc.ce.gov.br/index.php/o-paic/historico/historia>. Acesso em: 12 dez. 2015.

IPECE/SEPLAG. Perfil Municipal de Fortaleza. Tema VIII: O Mapa da Extrema Pobreza - Ceará, Informe $n^{\circ} 43$, Nov/2012. Fortaleza. Disponível em: <http://www.ipece.ce.gov.br/informe/Ipece_Informe_43_05_novembro_2012.pdf>. Acesso em: 12 dez. 2015.

FERNANDES, Reynaldo. Índice de desenvolvimento da educação básica - Série Documental. Brasília: Instituto Nacional de Estudos e Pesquisas Educacionais Anísio Teixeira, 2007.

FERNANDES, Reynaldo; GREMAUD, Amaury. Qualidade da educação básica: avaliação, indicadores e metas. In: VELOSO, Fernando et al. (Orgs.). Educação básica no Brasil: construindo o país do futuro. Rio de Janeiro: Elsevier, 2009.

FORTALEZA, PREFEITURA MUNICIPAL. Desenvolvimento Humano por Bairro em Fortaleza. Secretaria Municipal de Desenvolvimento Econômico (SDE), Fortaleza, 2014. Disponível em: <https://pt.calameo.com/read/0032553521353dc27b3d9>. Acesso em: 03 dez. 2015.

Diretrizes Curriculares para o Ensino Fundamental do Sistema Público Municipal de Ensino de Fortaleza, Volume 2. Edições SME, 2011a.

Lei $n^{\circ}$ 9.441, de 30 de dezembro de 2008. Aprova o Plano Municipal de Educação e dá outras providências. Diário Oficial do Município, Fortaleza, CE, n. 13.997, 05 de fev. 2009. Ano LVI, p.01-46. Disponível em: <http://apps.fortaleza.ce.gov.br/diariooficial/downloaddiario.php?objectId=workspace://SpacesStore/b2ee66d0-3d7d-4a61-8666-fedeadd4a927;1.1\&numero=13997> . Acesso em: 03 dez. 2015.

Portaria n ${ }^{\circ} 174$, de 11 de julho de 2008. Institui a coordenação pedagógica nas Escolas da Rede Municipal de Ensino, e regulamenta seu exercício, na forma que indica. Diário Oficial do Município, Fortaleza, CE, n. 13.859, 16 jul. 2008. Ano LVI, p. 38-39. Disponível em: < http://apps.fortaleza.ce.gov.br/diariooficial/download-diario.php?objectId=workspace://SpacesStore/84ca46925e52-4e53-a77f-db6feaaf0a3d;1.1\&numero=13859>. Acesso em: 03 dez. 2015.

\section{POLÊM!CA $\mid$ LABORE}

Polêmica - Revista Eletrônica da Uerj - Rua São Francisco Xavier, 524, $1^{\circ}$ andar bloco D, sl.1001 • Tels.: +55 21 2334-4088 / 4087 • http://www.e-publicacoes.uerj.br/index.php/polemica/index http://www.labore.uerj.br • laboreuerj@yahoo.com.br 
FREITAS, Dirce Nei Teixeira de. A avaliação da educação básica no Brasil: dimensão normativa, pedagógica e educativa. Campinas: Autores Associados, 2007.

HADDAD, F. O plano de desenvolvimento da educação: razões, princípios e programas. Brasília: Instituto Nacional de Estudos e Pesquisas Educacionais Anísio Teixeira, 2008.

INSTITUTO UNIBANCO. Anuário da Educação de Fortaleza 2012-2013. Disponível em: <http://www.institutounibanco.org.br/blog/2013/08/12/conheca-o-anuario-brasileiro-da-educacao-basica-2013>. Acesso em: 02 out. 2015.

LIBÂNEO, José Calos; OLIVEIRA, João Ferreira de; TOSCHI, Mirza Seabra. Educação escolar: políticas, estrutura e organização. 10. ed. São Paulo: Cortez, 2012. (Coleção Docência em Formação).

MAGALHÃES, Antônio Germano, Jr.; FARIAS, Maria Adalgiza; LIMA, Diva. Política de Avaliação Educacional no Estado do Ceará: Histórico dos Programas de Avaliação da Secretaria de Educação Básica do Ceará. In: XXI Encontro de Pesquisa Educacional do Norte e Nordeste - EPENN - Recife, 2013. Anais... 2013.

MINAYO, Maria. Cecília. Sousa. (Org.). Pesquisa social: teoria, método e criatividade. Rio de Janeiro: Vozes, 2001.

PESTANA, Maria Inês. Avaliação Educacional - o Sistema Nacional de Avaliação da Educação Básica. In: RICO, Elizabeth Melo (org.). Avaliação de políticas sociais: uma questão em debate. 5. ed. São Paulo: Cortez: Instituto de Estudos Especiais, 2007. p. 53- 63.

ONU/PNUD - 2013. Atlas do Desenvolvimento Humano no Brasil com dados do Censo 2010. Disponível em: <http://www.atlasbrasil.org.br/2013>. Acesso em: 03 jul. 2018.

Recebido em: 31/05/2017.

Aceito em: 31/05/2018.

\section{POLÊM!CA | LABORE}

Polêmica - Revista Eletrônica da Uerj - Rua São Francisco Xavier, 524, $1^{\circ}$ andar bloco D, sl.1001 • Tels.: +55 21 2334-4088 / 4087 • http://www.e-publicacoes.uerj.br/index.php/polemica/index http://www.labore.uerj.br • laboreuerj@yahoo.com.br 